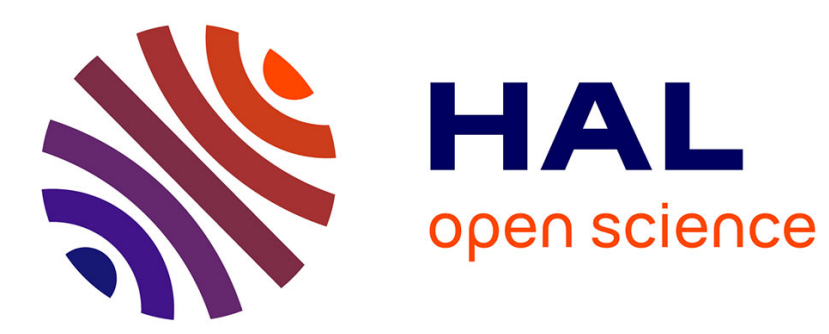

\title{
Electrical and Piezoelectric Behavior of Polyamide/PZT/CNT Multifunctional Nanocomposites
}

Delphine Carponcin, Eric Dantras, Jany Dandurand, Gwenaëlle Aridon, Franck Levallois, Laurent Cadiergues, Colette Lacabanne

\section{To cite this version:}

Delphine Carponcin, Eric Dantras, Jany Dandurand, Gwenaëlle Aridon, Franck Levallois, et al.. Electrical and Piezoelectric Behavior of Polyamide/PZT/CNT Multifunctional Nanocomposites. Advanced Engineering Materials, 2014, 16 (8), pp.1018-1025. 10.1002/adem.201300519 . hal-03464934

\section{HAL Id: hal-03464934 \\ https://hal.science/hal-03464934}

Submitted on 3 Dec 2021

HAL is a multi-disciplinary open access archive for the deposit and dissemination of scientific research documents, whether they are published or not. The documents may come from teaching and research institutions in France or abroad, or from public or private research centers.
L'archive ouverte pluridisciplinaire HAL, est destinée au dépôt et à la diffusion de documents scientifiques de niveau recherche, publiés ou non, émanant des établissements d'enseignement et de recherche français ou étrangers, des laboratoires publics ou privés. 


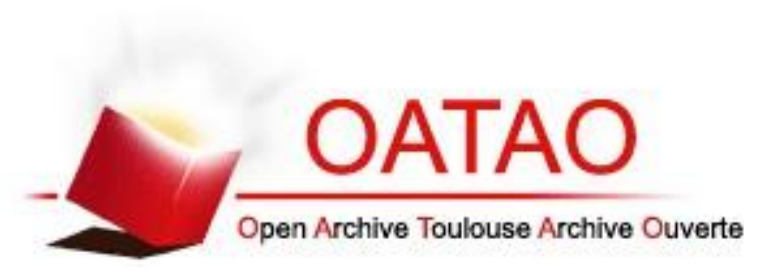

Open Archive Toulouse Archive Ouverte (OATAO)

OATAO is an open access repository that collects the work of Toulouse researchers and makes it freely available over the web where possible.

This is an author-deposited version published in: http://oatao.univ-toulouse.fr/ Eprints ID: 13974

Identification number: DOI: 10.1002/adem.201300519

Official URL: http://dx.doi.org/10.1002/adem.201300519

\section{To cite this version:}

Carponcin, Delphine and Dantras, Eric and Dandurand, Jany and Aridon, Gwenaëlle and Levallois, Franck and Cadiergues, Laurent and Lacabanne, Colette Electrical and Piezoelectric Behavior of Polyamide/PZT/CNT Multifunctional Nanocomposites. (2014) Advanced Engineering Materials, vol. 16 ( $\left.{ }^{\circ} 8\right)$. pp. 1018-1025. ISSN 1438-1656

Any correspondence concerning this service should be sent to the repository administrator: staff-oatao@inp-toulouse.fr 


\title{
Electrical and Piezoelectric Behavior of Polyamide/PZT/ CNT Multifunctional Nanocomposites
}

\author{
By Delphine Carponcin, Eric Dantras, ${ }^{*}$ Jany Dandurand, Gwenaëlle Aridon, \\ Franck Levallois, Laurent Cadiergues and Colette Lacabanne
}

Three-phase polyamide 11 (PA 11)/lead zirconate titanate (PZT)/carbon nanotubes (CNT) composites are elaborated by extrusion. The influence of inorganic particles on the electrical properties of conductive composites and the influence of conductive particles on the ferroelectric properties of organic/inorganic composites are both studied. Inorganic particles do not modify the establishment of the electrical percolation path of CNTs either regarding the percolation threshold value or the conductivity reached above this insulator-conductive transition. The dielectric permittivity of twophase PA 11/PZT composites is improved with the addition of only $0.2 \%$ in volume of CNTs. This three-phase composite could be proposed for actuation, energy harvesting and damping performances enhancement.

\section{Introduction}

In recent years, multifunctional composites have attracted great interest for achieving several properties by mean of only one material. For space industry, one part of the needs is focused on developing lightweight electroactive actuators and sensors. These piezoelectric based systems may be employed for adaptive and opening structures such as mirrors, antennas and solar panels. Piezoelectric polymers like poly(vinylidene fluoride) (PVDF), copolymer of vinylidene fluoride trifluoroethylene (P(VDF-TrFE)) and polyamide 11 (PA 11) offer good electromechanical coupling coefficients and high ductility. ${ }^{[1-3]}$ Nevertheless, the poling fields required to obtain a piezoelectric response are up to 10 times higher than the ones employed for poling inorganic ceramics such as lead zirconate titanate (PZT). ${ }^{[4]}$ These last ones possess high electromechanical properties over a wide temperature range. To take advantage of both organic and inorganic materials, spherical inclusions of ferroelectric ceramic have been introduced in a polymer matrix

[*] Dr. E. Dantras, Dr. D. Carponcin, J. Dandurand

Prof. C. Lacabanne

Physique des Polymères, CIRIMAT, Université de Toulouse, 31062 Toulouse Cedex, France

E-mail: eric.dantras@univ-tlse3.fr

Dr. G. Aridon, Dr. F. Levallois

EADS Astrium Satellites, 31 avenue des Cosmonautes, 31401 Toulouse, France

L. Cadiergues

Centre National d'Etudes Spatiales, 18 avenue Edouard Belin, 31401 Toulouse, France to offer a $0-3$ connectivity composite. ${ }^{[5-8]}$ In order to maintain the mechanical properties of the polymer for a higher volume fraction of inorganic particles, micronic fillers have been substituted by submicronic ones. ${ }^{[9-12]}$ As a function of the final required mechanical properties, other solutions are proposed for offering a flexible piezoelectric material by introducing piezoelectric structural fiber in a polymer matrix. ${ }^{[13,14]}$

Applying an electric field to ferroelectric ceramics induce the orientation of electric dipoles and the appearance of the piezoelectric property. The same protocol is required for piezoelectric composite: the entire composite undergoes the poling process to reach the ferroelectric particles. Consequently, the dielectric permittivity of the polymer matrix is one of the key parameters for poling such composites. It governs the effective poling field and the remanent polarization.

The main route for improving the dielectric permittivity of piezoelectric composites is to introduce conductive particles in the polymer matrix. ${ }^{[15-22]}$ By creating new interfaces in the three-phase system, the dielectric permittivity is locally risen which leads to an increase of the macroscopic one. Several authors describe an increase of the piezoelectric properties with the conductive particles fraction in three phase composites. For a same poling field intensity, the remanent polarization and the piezoelectric coefficient $d_{33}$ are higher with the introduction of conductive fillers (carbon nanotubes, carbon black, graphite, or aluminum particles). ${ }^{[23-28]}$ Regarding actuator applications, the electrostriction phenomenon is also greatly improved with the addition of conductive fillers at a rate lower than the percolation threshold. ${ }^{[29-31]}$ It has to be noticed that these three-phase composites are also interesting for their damping function. ${ }^{[32-34]}$ Indeed, the piezoelectric 
property enables the conversion of mechanical energy into electric one: then, conductive fillers ensure a local dissipation of the created electric potential.

The main purpose of this work is the elaboration and characterization of electrical, dielectric, and piezoelectric properties of a three-phase composite. Polyamide 11 (PA 11) has been chosen as a model thermoplastic polymer. PZT particles and carbon nanotubes have been respectively selected as piezoelectric and conductive fillers. For a given volume fraction of PZT particles, the establishment of the electrical conductivity brought by the CNTs will be studied as well as the composite dielectric permittivity and piezoelectric coefficient to clarify the synergy between both fillers.

\section{Results and Discussion}

\subsection{Electrical Conductivity}

The evolution of the electrical conductivity of PA 11/PZT 30 vol\%/CNT composites with the CNT volume fraction is reported Figure 1. Each point corresponds to the average of two values obtained for two different samples stem from the same extrusion process. An abrupt variation of the conductivity (nine decades) highlights an electrical percolation phenomenon defined by the percolation theory as an insulatorconductor transition. ${ }^{[35]}$ The following scaling equation links the evolution of the conductivity to four parameters:

$\sigma=\sigma_{0}\left(p-p_{\mathrm{c}}\right)^{t}$

where $\sigma_{0}$ is a constant, $p$ the CNTs weight fraction, $p_{\mathrm{c}}$ the CNTs weight fraction at the percolation threshold, and $t$ the critical exponent. The best-fitted values are for $p_{\mathrm{c}}=0.38 \mathrm{vol} \%$, $\sigma_{0}=1.7 .10^{-2} \mathrm{~S} \mathrm{~m}^{-1}$, and $t=2.5 \pm 0.3$. The $t$ exponent is closed to the universal value predicted by Stauffer associated with a 3D percolation network. ${ }^{[36]}$

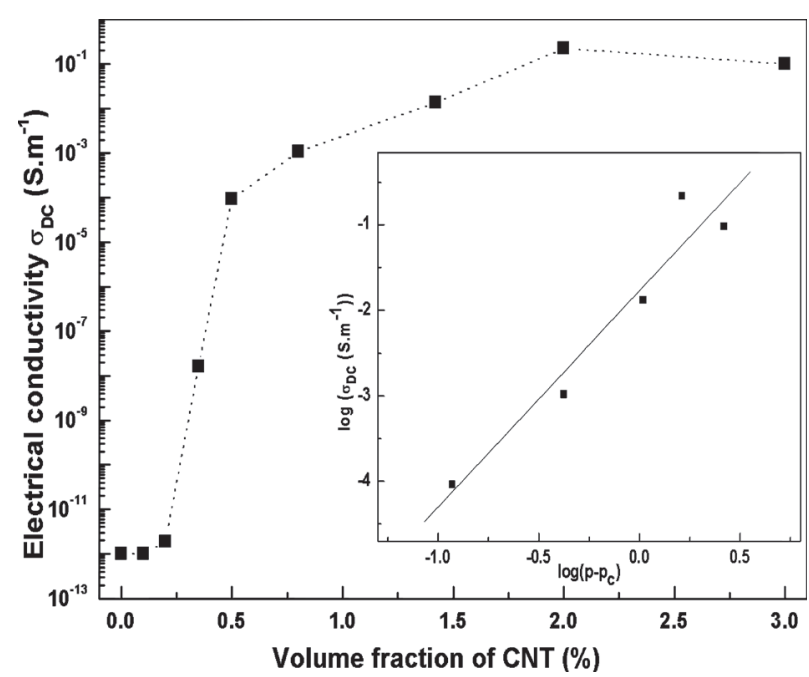

Fig. 1. Dependence of the $\sigma_{D C}$ conductivity on the CNTs volume fraction at $25^{\circ} \mathrm{C}$ for $P A$ $11 / P Z T 30$ vol $\% / C N T$ composites. The insert shows $\log \sigma$ versus $\log \left(p-p_{c}\right)$ and the solid line corresponds to the best fit.
Figure 2 compares the electrical percolation thresholds of PA 11/CNT and PA 11/PZT/CNT composites for CNT volume percentages calculated as a function of the volume occupied only by the polymer matrix and the CNTs (PZT volume is not taken into account anymore) ${ }^{[37]}$ It appears that the insulatorconductor transitions occur for the same CNT concentration in case of both composites. PZT particles do not hinder the establishment of the percolating path and no particular interactions exist between both different fillers. The random orientation of carbon nanotubes in the polymer matrix is not disturbed by the presence of the spherical PZT particles.

Similar studies on polymer composites with clay and CNTs loading have been published. For a polypropylene (PP)/clay/ CNT, Levchenko et al. ${ }^{[38]}$ observed a decrease of the percolation threshold value with the introduction of spherical insulating particles ( $0.68 \mathrm{vol} \%$ instead of $0.95 \mathrm{vol} \%)$. In polyepoxy/clay/ CNT composites, Liu et al. ${ }^{[39]}$ showed a decrease of the insulator-conductor transition from 0.05 to $0.01 \mathrm{wt} \%$ of CNTs with the addition of $2 \mathrm{wt} \%$ of clay particles. Both sets of data have been explained by a more homogeneous dispersion of carbon nanotubes in the polymer matrix upon clay loading. It is also interesting to report here data published by Meincke et al. ${ }^{[40]} 55 \mathrm{wt} \%$ of acrylonitrile/butadiene/styrene (ABS) was dispersed in a polyamide 6 matrix. The percolation threshold of CNTs in PA 6 was divided by two due to ABS. Transmission electron microscopy micrographs showed conductive fillers exclusively dispersed in the PA 6 phase, which explains this decrease. Three main parameters influence the percolation threshold value: the concentration and the size of the insulating particles but also their interactions with the conductive fillers.

\subsection{Glass Transition}

The influence of PZT particles and carbon nanotubes on the physical structure of the polymer matrix has also been studied. Figure 3 presents the glass transition temperature $\left(T_{\mathrm{g}}\right)$ of PA

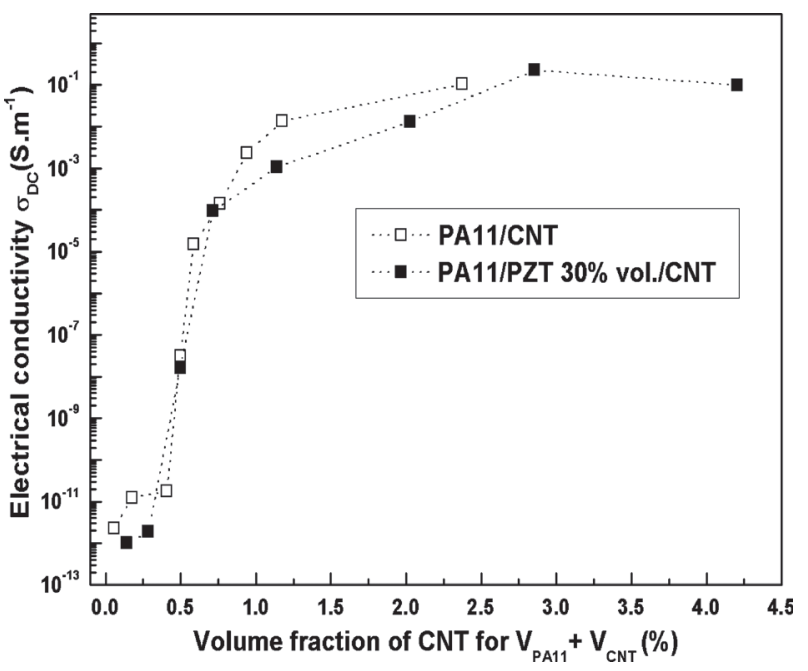

Fig. 2. Dependence of the $\sigma_{D C}$ conductivity on the CNTs volume fraction at $25^{\circ} \mathrm{C}$ for $P A$ 11/CNT and PA 11/PZT 30 vol\%/CNT composites. 


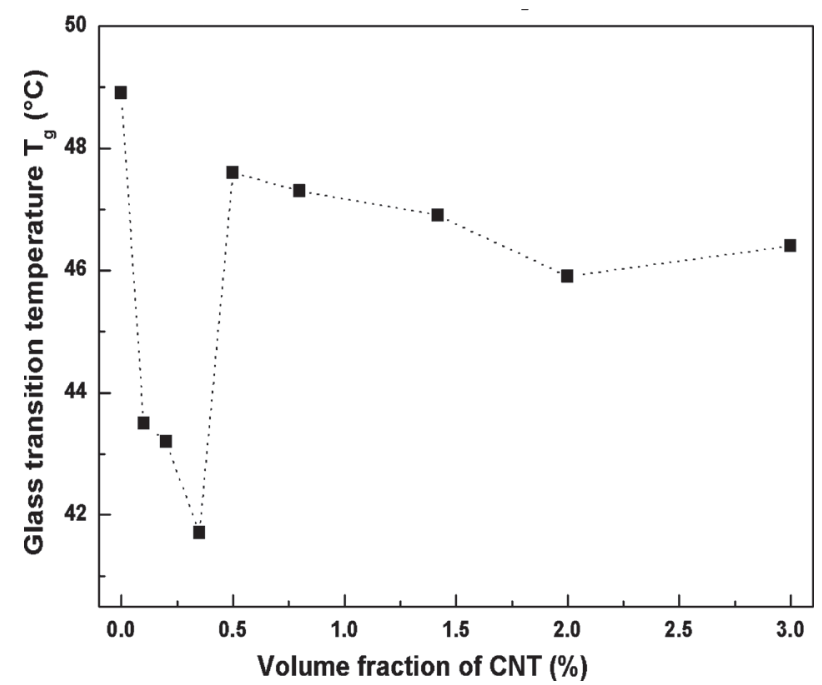

Fig. 3. Variation of the glass transition temperature $T_{g}$ obtained by DSC with CNT content in PA 11/PZT 30 vol\%/CNT composite.

11/PZT 30 vol\%/CNTs composites recorded at the first temperature scan as a function of CNT concentration.

For the PA $11 / \mathrm{PZT} 30 \mathrm{vol} \%$ composite $(0 \%$ of $\mathrm{CNT})$, the $T_{\mathrm{g}}$ is closed to $49^{\circ} \mathrm{C}$. A depression of the glass transition temperature $\left(5-6^{\circ} \mathrm{C}\right)$ is observed for the PA $11 / \mathrm{PZT} / \mathrm{CNT}$ composite loaded at $0.35 \mathrm{vol} \%$ of CNTs. This decrease starts from $0.1 \mathrm{vol} \%$ of CNTs. From 0.5 to $3 \%$ of CNTs, $T_{\mathrm{g}}$ stays nearly stable. These observations are attributed to a specific conformation of the CNT network at the electrical percolation threshold.

\subsection{Dielectric Permittivity}

Figure 4 shows the influence of ceramic and conductive fillers on the real part of the dielectric permittivity. The dielectric permittivity of neat PA 11 is equal to 3 and increases to 6.6 with the introduction of $30 \mathrm{vol} \%$ of PZT particles (values

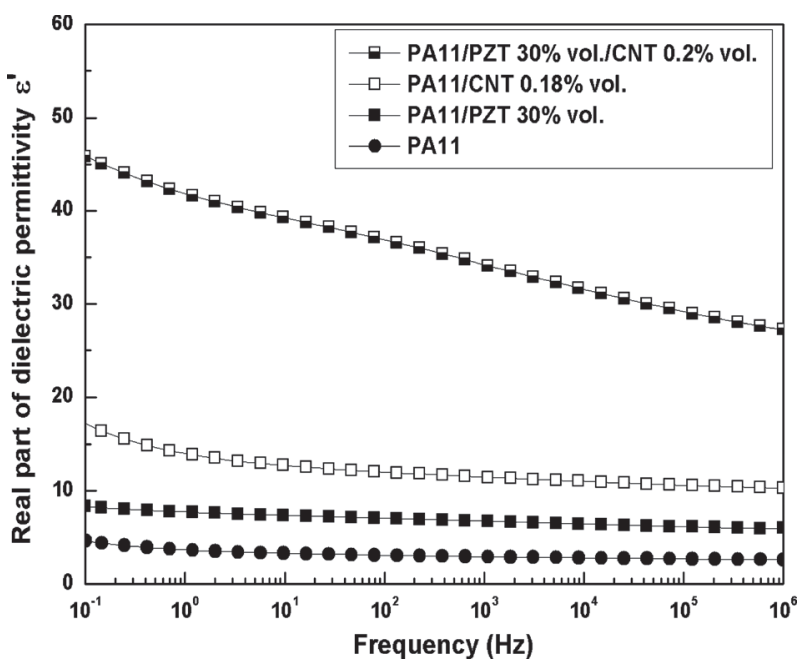

Fig. 4. Real part of the dielectric permittivity $\varepsilon^{\prime}$ of PA 11, PA 11/PZT 30 vol\%, PA11/ CNT 0.18 vol $\%$ and PA 11/PZT 30 vol $\% / C N T 0.2$ vol $\%$ composites, measured at $26^{\circ} \mathrm{C}$, as a function of frequency. taken at $1 \mathrm{kHz}$ ). This increase is attributed to a relatively high permittivity of ceramic particles but also to the appearance of an interfacial polarization at polymer/particles interfaces. It is interesting to compare this result with the one obtained with the introduction of $0.18 \mathrm{vol} \%$ of carbon nanotubes in PA 11 . The permittivity increases up to 12: carbon nanotubes play the role of electronic micro reservoirs, which induce charge storage at the polymer/CNT interfaces. Dang et al. ${ }^{[21]}$ reports a similar behavior for PVDF/CNT composites. Both intrinsic electrical conductivity and aspect ratio of conductive fillers are key factors in the permittivity enhancement. ${ }^{[21]}$ Upon introduction of both ceramic and conductive fillers in the polymer matrix, the PA 11/PZT 30 vol\%/CNT 0.2 vol\% composite acquires a dielectric permittivity of 32 showing a synergy effect between particles since this value is superior to $\varepsilon$ (PA 11/ CNT $0.18 \mathrm{vol} \%)+\varepsilon$ (PA 11/PZT $30 \mathrm{vol} \%)$.

Figure 4 also reveals an increase of the dielectric permittivity at low frequencies for composites loaded with carbon nanotubes. Low frequency conductivity phenomenon contributes to increase the charge density at the polymer/fillers interfaces.

Figure 5 points out the evolution of the real part of the dielectric permittivity of PA $11 / \mathrm{CNT}$ and PA $11 / \mathrm{PZT}$ $30 \mathrm{vol} \% / \mathrm{CNT}$ composites as a function of CNT volume fraction. All composites are situated below their electrical percolation threshold. The dielectric permittivity increases with a very low concentration of carbon nanotubes and the evolution between different volume fractions is less pronounced. The electronic reservoirs represented by CNTs induced macrodipoles responsible for the permittivity raise. This increase is more intense for PA 11/PZT/CNT composite. The dielectric permittivity of the polymer matrix is extrinsically increased by the introduction of conductive fillers under their percolation threshold. The influence of the electric field on PZT particles during permittivity measurements becomes more effective and PA 11/PZT/CNT composites offer a higher dielectric permittivity than the PA 11/PZT one.

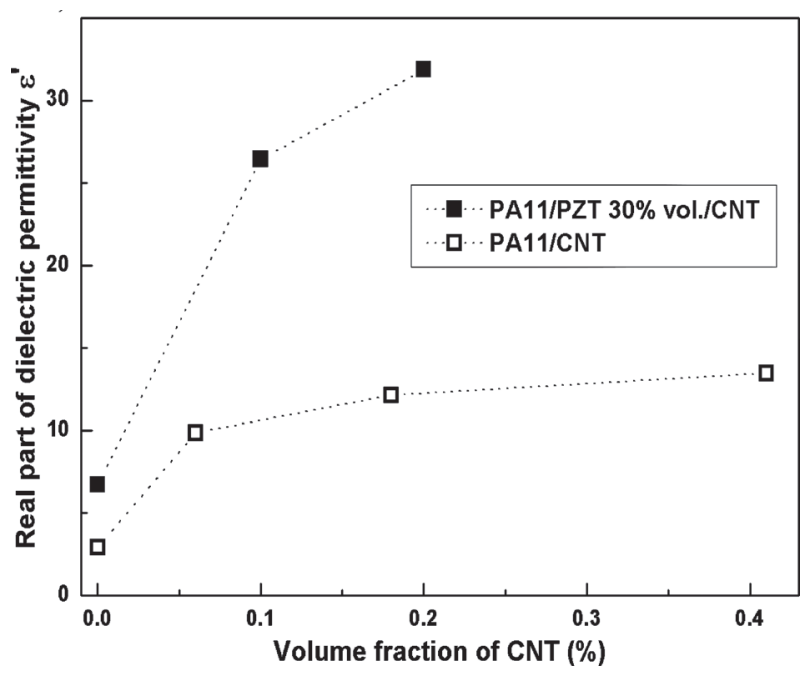

Fig. 5. Real part of the dielectric permittivity $\varepsilon^{\prime}$ of PA11/PZT $30 \mathrm{vol} \% / C N T$ and of PA11/ CNT composites as a function of CNT volume fraction. 


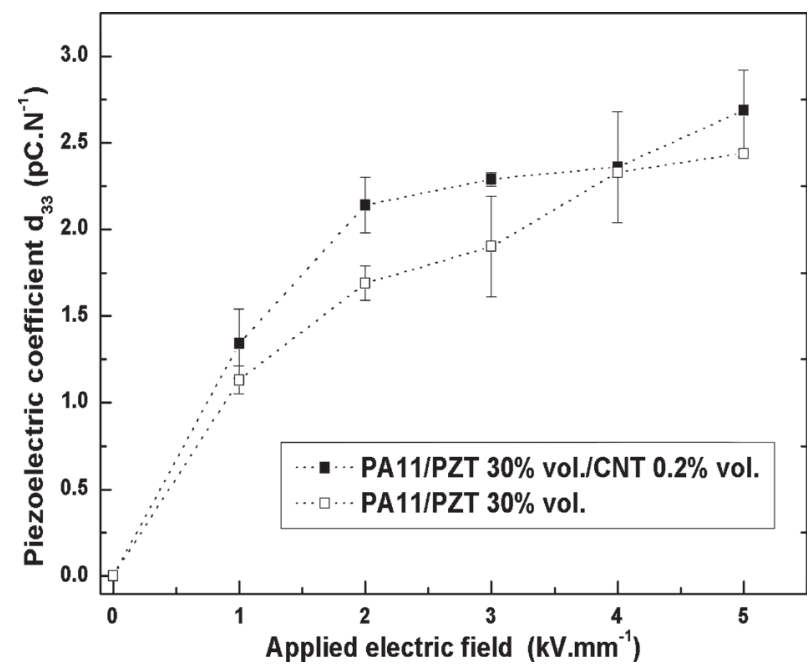

Fig. 6. Piezoelectric coefficient $d_{33}$ of PA11/PZT $30 \mathrm{vol} \%$ and PA11/PZT $30 \mathrm{vol} \% / C N T$ composites as a function of electric field during the poling process.

\subsection{Piezoelectric Coefficient}

The influence of carbon nanotubes (at $0.2 \mathrm{vol} \%$ ) on the piezoelectric coefficient $d_{33}$ of PA $11 / \mathrm{PZT}$ composite is presented in Figure 6 as a function of the applied electric field, during the poling process. Carbon nanotubes induce a maximum $d_{33}$ increase of $26 \%$ for a poling field of $2 \mathrm{kV} \mathrm{mm}^{-1}$. With the presence of CNTs, the local electric field is more important and the PZT particles poling more efficient. ${ }^{[41]}$ Beyond $5 \mathrm{kV} \mathrm{mm}^{-1}$, the samples loaded with conductive fillers undergo an electrical breakdown.

For the rest of the work, a blocking electrode (made of neat PA 11) is used to avoid electrical breakdown. The composites are poled under a $5 \mathrm{kV} \mathrm{mm}^{-1}$ electric field, which is calculated by taking into account the sample and the blocking electrode thicknesses. Figure 7 shows the evolution of the piezoelectric coefficient $d_{33}$ of PA 11/PZT $30 \mathrm{vol} \% / \mathrm{CNT}$ composites as a

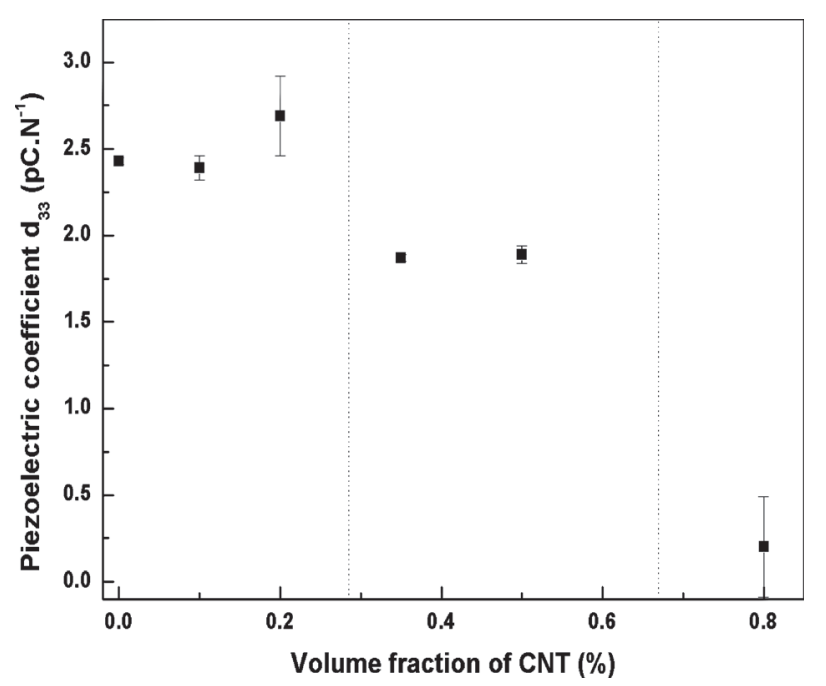

Fig. 7. Piezoelectric coefficient $d_{33}$ of PA11/PZT $30 \mathrm{vol} \% / C N T$ composites as a function of CNT volume fraction. function of the CNT volume fraction. The $d_{33}$ coefficient increases until $0.2 \mathrm{vol} \%$ of CNTs. These composites are situated below the percolation threshold. The electric field raises locally with the effect of carbon nanotubes and the poling action is more efficient. Regarding composites with 0.35 and $0.5 \mathrm{vol} \%$ CNT loading (around the electrical percolation threshold), the piezoelectric coefficient undergoes a $43 \%$ decrease. The electronic flow stopped by the blocking electrode is amplified: the trapped charges induce a depolarization field that limits the applied poling field. The electrical conductivity of the composite loaded at $0.8 \mathrm{vol} \% \mathrm{CNTs}$ (above the percolation threshold) is high enough to completely cancel the applied field. Such behavior was also highlighted by Liu et al. ${ }^{[27]}$ in PVC/PZT/graphite composites for higher PZT loading.

\subsection{Influence of the Matrix Dielectric Permittivity on the} Piezoelectric Strain Coefficient

For the $d_{33}$ coefficient measurement, a sinusoidal stress is applied. Under this stress, the surface charge density upon the ceramic surfaces is increased. By interfacial polarization, a polarization appears within the polymer matrix. Its quantification (in Coulomb), reported to the applied stress, allows us to access to the piezoelectric strain coefficient in $\mathrm{pC} \mathrm{N} \mathrm{N}^{-1}$.

In order to further understand the polymer dielectric permittivity influence on the electroactivity of this kind of composites, PZT particles have been dispersed in a high permittivity polymer, the PVDF-TrFRE-CFE $\left(\varepsilon^{\prime}=17.3\right)$.

The evolution of the piezoelectric strain coefficient of PA 11/ PZT, PVDF-TrFRE-CFE/PZT and PA 11/PZT/CNT 0.2 vol\% composites (PZT at $30 \%$ in volume for the three composites) and the dielectric permittivity of their respective matrix are represented in Table 1. It has to be noted that in case of the PA $11 / \mathrm{PZT} / \mathrm{CNT}$ composite, the PA $11 / \mathrm{CNT} 0.18 \mathrm{vol} \%$ is considered as the matrix. Each composite have undergone the same poling process (application of a $5 \mathrm{kV} \mathrm{mm}^{-1}$ electrical field during $15 \mathrm{~min}$ at $80^{\circ} \mathrm{C}$ ).

Table 1 shows that the best $d_{33}$ coefficient is obtained with the PVDF-TrFE-CFE matrix (16.2 pC.N $\left.{ }^{-1}\right)$. Compared to the PA $11 /$ PZT composite, by multiplying the matrix permittivity by 5.8 , the piezoelectric coefficient is increased by a factor of six. It is interesting to compare this result with the one obtained with the three-phase composite. The introduction of $0.18 \mathrm{vol} \%$ of CNTs leads to a polymer permittivity four times higher than the PA 11/PZT composite; therefore the $d_{33}$ coefficient remains the same than the PA 11/PZT composite one. This result brings the conclusion that the polarization of ceramic particles is more

Table 1. Comparison of piezoelectric coefficients $d_{33}$ of PA 11/PZT 30 vol\%, PVDFTrFRE-CFE/PZT 30 vol $\%$ and PA 11/PZT 30 vol\%/CNT 0.2 vol $\%$ composites and the dielectric permittivity of their matrix (in bold) at $26^{\circ} \mathrm{C}$ and $1 \mathrm{kHz}$.

\begin{tabular}{lccc} 
& & & \\
Composite & PA11/PZT & PVDF-TrFE-CFE/PZT & PA11/PZT/CNT \\
\hline$\varepsilon^{\prime} /$ matrix & 3 & 17.3 & 12 \\
$d_{33}\left(\mathrm{pC} \mathrm{N}^{-1}\right)$ & 2.7 & 16.2 & 2.7
\end{tabular}


efficient in case of an intrinsically high dielectric permittivity of the polymer matrix. This may be explained by a homogeneous distribution of electrical dipoles from the polymer chain compared to the one induced by the $\mathrm{CNT}$ / polymer interfaces. Another phenomenon is susceptible to play a role in these results. Actually, the conductive fillers may be inert during the $d_{33}$ measurement process. The CNTs are efficient under an electrical excitation (for the permittivity measurement or during the poling process) but inefficient when a stress is applied for charge density measurement (piezoelectric coefficient measurement).

\section{Conclusion}

A novel three-phase composite with submicronic ferroelectric particles (PZT) and conductive carbon nanotubes embedded into a semi-crystalline thermoplastic matrix (polyamide 11) has been elaborated by extrusion (molten way).

These PA 11/PZT/CNT nanocomposites have shown an electrical percolation threshold for a very low CNT concentration $(0.35 \mathrm{vol} \%)$. Data show that insulating spherical PZT particles have no influence onto the percolating path tortuosity. SEM images show that PZT particles and CNTs are well dispersed in the polymer matrix at a micronic scale. Then, the absence of interaction between fillers is confirmed.

It is also interesting to note that a $5^{\circ} \mathrm{C}$ depression has been observed on glass transition temperatures at the electrical percolation threshold of the PA 11/PZT/CNT composites. Analogous results were obtained in a previous work on PA 11/ CNT composites. In other words, PZT does not play any role on the specific conformation of carbon nanotubes at the percolation threshold.

The dielectric permittivity of the PA 11 matrix has been increased by 10 times thanks to the simultaneous introduction of PZT particles and CNTs. With their high aspect ratio and their good intrinsic electrical conductivity, CNTs promote the formation of dipoles at the polymer/CNT interfaces, which contribute to the enhancement of the polymer dielectric permittivity. A synergy between both types of fillers has been shown on the dielectric permittivity of the PA 11/PZT/CNT three phase composite.

During the poling process, the local electric field is amplified by carbon nanotubes and the piezoelectric activity of PZT particles is increased. The use of a blocking electrode has highlighted three behaviors, which follow the conductive behavior of these three-phase composites. Below the percolation threshold, the piezoelectric coefficient is increased by the presence of conductive fillers but since the electrical percolation is reached, the appearance of a depolarization field lowers the poling field efficiency.

Finally, an industrial process was employed to prepare a three-phase composite showing a good filler dispersion. This work opens opportunities to develop new thermoplastic-based composite with a great enhancement of the polymer dielectric permittivity.

\section{Experimental Section}

\subsection{Materials}

The Polyamide 11 (PA 11) was chosen as polymer matrix for its good mechanical properties: its tensile modulus is about $1 \mathrm{GPa}$. This semi-crystalline thermoplastic polymer has a glass transition temperature and a melting point of 46 and $189^{\circ} \mathrm{C}$, respectively. Thermal degradation of the polymer operates at $436^{\circ} \mathrm{C}$. PA 11 was provided as a powder $(30 \mu \mathrm{m})$ by Arkema (France) in its paraelectric state.

Lead zirconate titanate $\left(\mathrm{Pb}\left[\mathrm{Zr}_{x} \mathrm{Ti}_{1-x}\right]\right)$, also called PZT, is well known for its high ferroelectric properties at the morphotropic phase boundary due to the coexistence of the tetragonal and rhombohedral crystalline phases. ${ }^{[42]}$ PZT particles were provided by Ferroperm (Denmark) with a mean diameter of $900 \mathrm{~nm}$. Bulk ceramic exhibits a Curie temperature of $235^{\circ} \mathrm{C}$ and a piezoelectric coefficient $d_{33}$ of 575 $\mathrm{pC} \mathrm{N}^{-1}$ (given by the manufacturer in the bulky state). Its coercitive field is about $5-10 \mathrm{kV} \mathrm{mm}^{-1}$. Previous X-ray diffraction measurements have shown the ferroelectric properties of these inorganic fillers so that they can acquire piezoelectricity after a poling step. ${ }^{[10]}$

Carbon nanotubes were synthesized by catalytic chemical vapor deposition by Marion Technology (France) and are mostly double-walled ( $80 \mathrm{wt} \%$ ). They are characterized by a high aspect ratio (length over diameter) of $10^{3}-10^{4}{ }^{[43]}$

\subsection{Nanocomposite Processing}

PA 11/PZT/CNT composites were elaborated by extrusion with a twin screw extruder (Minilab II from Haake). This method consists in introducing fillers in the polymer matrix in a molten state. For the sake of simplicity, the PZT particle volume fraction was fixed at $30 \%$ for ensuring the best compromise between electro active properties and mechanical properties.

PZT particle size has been optimized. At first, PZT particles (900 and $1200 \mathrm{~nm}$ ) have been introduced in polyamide 11 matrix (at $0,15,30$, and $45 \mathrm{vol} \%$ ) by extrusion and the obtained samples have been characterized by longitudinal traction tests. Figure 8 shows that, qualitatively the tensile modulus increases with PZT concentration. For composites with $900 \mathrm{~nm}$ particles, the maximum stress is close to the PA 11 one for volume fraction of 15 and $30 \%$ (between 35 and $40 \mathrm{MPa}$ ); the strain at break appears above $10 \%$. For the composites loaded at $45 \mathrm{vol}$ $\%$, the stress at break is $25 \mathrm{MPa}$ for a maximum strain below $5 \%$. Regarding composites loaded at $30 \mathrm{vol} \%$, the mechanical behavior shifts from a ductile to a fragile one's when particle size increases above micrometer.

In conclusion, PZT particle volume fraction has been fixed at $30 \%$ in volume and PZT particle diameter at $900 \mathrm{~nm}$ with the intention of ensuring the best compromise between high electroactive properties and preserved mechanical properties.

The main challenge of this study is to introduce at the same time two submicronic fillers of different nature with two distinct morphologies. Figure 9 illustrates the elaboration process of the nanocomposites. The first step consists in eliminating 

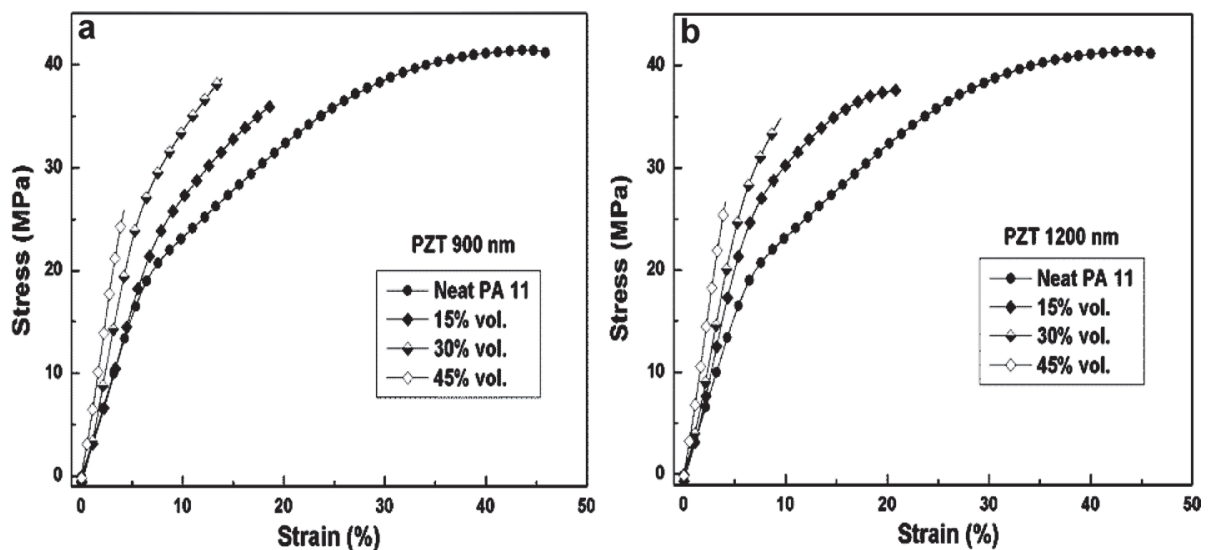

Fig. 8. Stress-strain curves of PA 11/PZT composites at different volume fractions $(0,15,30,45 \mathrm{vol} \%)$ for PZT particle size of (a) $900 \mathrm{~nm}$ and (b) $1200 \mathrm{~nm}$.

aggregates: for this purpose, PZT particles and CNTs were dispersed separately in acetone by ultra-sonication. PA 11 powder and acetone $+\mathrm{CNTs}$ have been then added successively to acetone + PZT mixture with an ultrasound step each time. At the end, the use of a rotary evaporator allows suppressing acetone rapidly and avoiding sedimentation and re-agglomeration of fillers. PZT particles and CNT are statistically dispersed in the PA 11 mixture and give rise to a viscous mixture, which is introduced in the twin-screw extruder.

The parameters governing the extrusion process, i.e. mixing temperature, mixing time, and screw rotation speed, were optimized in a previous work. ${ }^{[37]}$ The values were respectively: $210^{\circ} \mathrm{C}, 15 \mathrm{~min}$, and $30 \mathrm{rpm}$. CNTs present high electrostatic affinity between themselves but no significant interaction with inorganic spherical particles: in that case, extrusion parameters used for PA 11/CNT composite have been retained.

After the extrusion step, composites are hot pressed at $210^{\circ} \mathrm{C}$ in order to achieve films with a mean thickness of $150 \mu \mathrm{m}$. A poling step is required to orient PZT dipoles and

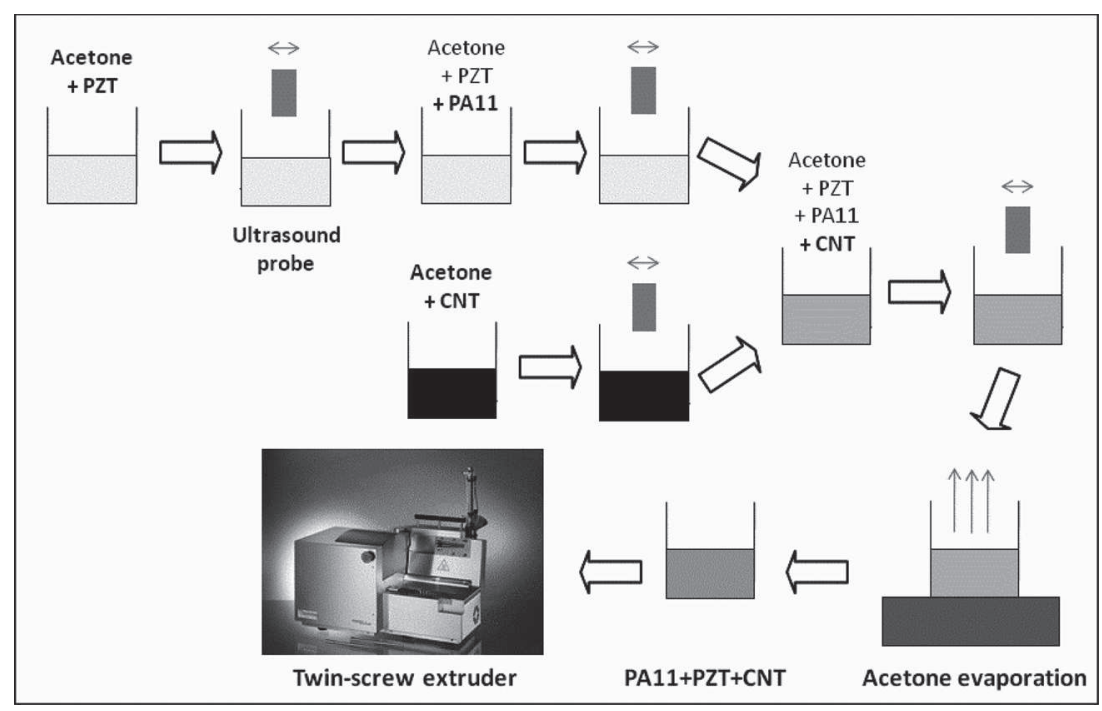

Fig. 9. Schematic of PA 11/PZT/CNT composite elaboration process. make PZT particles piezoelectric as well as nanocomposites: an electric field of $5 \mathrm{kV} \mathrm{mm}^{-1}$ during $15 \mathrm{~min}$ at $80^{\circ} \mathrm{C}$ is applied. ${ }^{[5,9]}$

\subsection{Sample Characterization}

\subsubsection{Scanning Electron \\ Microscopy}

A JEOL JSM 6700F scanning electron microscope with field emission gun (SEM-FEG) was used to observe filler dispersion in the polyamide matrix (Figure 10). As PZT density is higher than polymer one, backscattered electron detection was used and PZT particles appear as bright spherical entities in the background. They are covered by a thin layer of polymer. In spite of a lack of contrast, CNTs are still visible and are indicated by an arrow. Even at a micronic scale, PZT particles and CNTs are well dispersed in PA 11 and they do not present particular affinities between themselves.

\subsubsection{Differential Scanning Calorimetry}

The measurements of composite glass transition temperature were performed using a differential scanning calorimeter (Perkin-Elmer DSC7). The heating rate was $20^{\circ} \mathrm{C} \mathrm{min}{ }^{-1}$ from 20 to $210^{\circ} \mathrm{C}$. Sample weight was in the range $5-10 \mathrm{mg}$. All composites were subjected to thermal ageing at $25^{\circ} \mathrm{C}$ during $24 \mathrm{~h}$ to highlight the glass transition. The glass transition temperature was defined by the midpoint of the heat capacity step.

\subsubsection{Dynamic Dielectric Spectroscopy}

Electrical conductivity and dielectric permittivity measurements were carried out by recording the complex permittivity $\varepsilon^{*}(\omega)$ using a Novocontrol broadband dielectric spectrometer. Measurements were done in the frequency range from $10^{-2}$ to $10^{6} \mathrm{~Hz}$ at $26^{\circ} \mathrm{C}$.

The complex conductivity $\sigma^{*}(\omega)$ was extracted from the complex permittivity $\varepsilon^{*}(\omega)\left[\sigma^{*}(\omega)=i \omega \varepsilon_{0} \varepsilon^{*}(\omega)\right]$ and the real part of the complex conductivity, $\sigma^{\prime}(\omega)$, was investigated. The value of $\sigma^{\prime}(\omega)$ at $10^{-2} \mathrm{~Hz}$ was taken as dc conductivity $\sigma_{\mathrm{DC}}$. Regarding dielectric properties of insulating composites, the evolution of the real part of the complex permittivity $\varepsilon^{\prime}(\omega)$ was studied.

\subsubsection{Piezoelectric Measurements}

The final piezoelectric properties of the composites were obtained by poling the samples at $80^{\circ} \mathrm{C}$ under a static field comprised between 1 and $5 \mathrm{kV} \mathrm{mm}^{-1}$ for $15 \mathrm{~min}$. These conditions allow maximizing the orientation of inorganic dipoles in the applied electric field direction. Regarding 


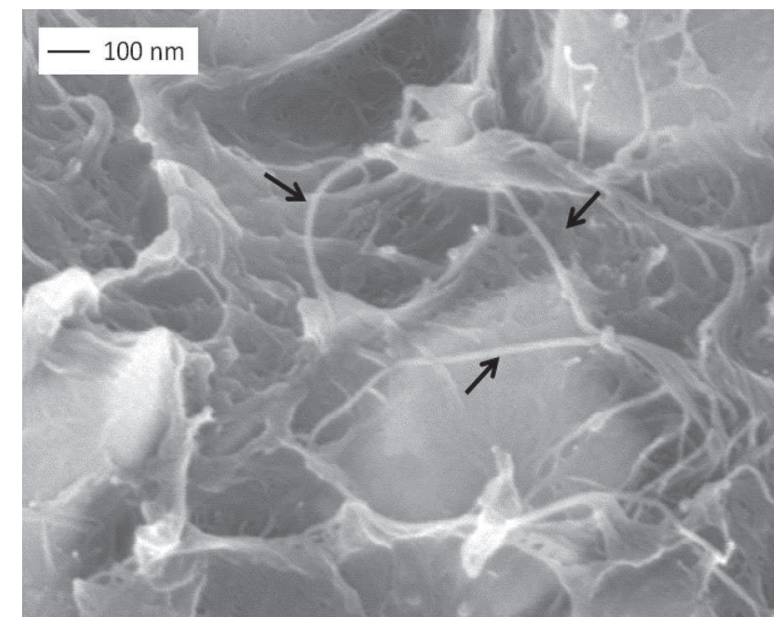

Fig. 10. Scanning electron microscopy image of a three-phase PA 11/PZT 30 vol\%/CNT 0.2 vol\% composite. Carbon nanotubes are indicated by arrows and PZT particles appear as light spherical shape in background.

the poling temperature, it is important to note that above the glass transition temperature of the polymer matrix, its dielectric permittivity increases due to the increase of the polymer molecular mobility; by this way, the efficiency of the poling step is improved. The electric field was turn off and the samples were short-circuited for $24 \mathrm{~h}$ before piezoelectric measurements.

Piezoelectric measurements were then carried out using a PM 200 piezometer supplied by Piezotest (UK), with a force of $0.25 \mathrm{~N}$ at $110 \mathrm{~Hz}$ in frequency. The piezoelectric coefficient $d_{33}$ $\left(\mathrm{pCN}^{-1}\right)$ is measured in the same direction than the poling field, following the relation:

$P=d_{33} \times \sigma$

where $P$ is the polarization $\left(\mathrm{C} \mathrm{m}^{-2}\right)$ and $\sigma$ the applied stress $\left(\mathrm{Nm}^{-2}\right)$.

[1] L. Ibos, A. Bernes, C. Lacabanne, Ferroelectrics 2005, 320, 483.

[2] G. Teyssedre, C. Lacabanne, Ferroelectrics 1995, 171, 125.

[3] P. Frübing, A. Kremmer, W. Neumann, R. GerhardMulthaupt, IEEE Trans. Dielec. Electr. Insul. 2004, 11, 271.

[4] T. M. Kamel, F. X. N. M. Kools, G. De With, J. Eur. Ceram. Soc. 2007, 27, 2471.

[5] T. Furukawa, K. Fujino, E. Fukada, Jpn. J. Appl. Phys. 1976, 15, 2119.

[6] T. Furukawa, K. Ishida, E. Fukuda, J. Appl. Phys. 1979, 50, 4904.

[7] K. Li, H. Wang, A. Ding, Polym. Sci. 2010, 52, 438.
[8] D. A. Van Den Ende, B. F. Bory, W. A. Groen, S. Van Der Zwaag, J. Appl. Phys. 2010, 107, 024107.

[9] J. F. Capsal, E. Dantras, J. Dandurand, C. Lacabanne, J. Non-Cryst. Solids 2007, 353, 4437.

[10] D. Carponcin, E. Dantras, J. Dandurand, C. Lacabanne, L. Laffont, L. Cadiergues, G. Aridon, F. Levallois, 53rd AIAA/ASME/AHS/ASC Struct. Struct. Dynamics Mater. Conf, Honolulu, Hawaî, 2012.

[11] C. David, J. F. Capsal, L. Laffont, E. Dantras, C. Lacabanne, J. Phys. D Appl. Phys. 2012, 45, 415305.

[12] S. K. Sharma, H. Gaur, M. Kulkarni, G. Patil, B. Bhattacharya, Compos. Sci. Technol. 2013, 77, 42.

[13] Y. Lin, H. A. Sodano, Adv. Funct. Mater. 2009, 19, 592.

[14] Y. Lin, J. W. Shaffer, H. A. Sodano, Smart Mater. Struct. 2010, 19, 124004.

[15] F. A. Hu, K. H. Lam, J. T. Fan, L. W. Chan, Polym. Test. 2013, 32, 927.

[16] J. Wang, N. Wei, F. Wang, C. Wu, S. Li, Polym. Bull. 2012, $68,2285$.

[17] Z. Ghallabi, M. Arous, A. Kallel, I. Royaud, G. Boiteux, G. Seytre, Int. Conf. Solid Dielectrics, Germany, 2010.

[18] S. H. Yao, Z. M. Dang, M. J. Jiang, J. B. Bai, Appl. Phys. Lett. 2008, 93, 182905.

[19] Z. M. Dang, L. Wang, Y. Yin, Q. Zhang, Q. Q. Lei, Adv. Mater. 2007, 19, 852.

[20] H. W. Choi, Y. W. Heo, J. H. Lee, J. J. Kim, H. Y. Lee, Appl. Phys. Lett. 2006, 89, 132910.

[21] Z. M. Dang, L. Z. Fan, Y. Shen, C. W. Nan, Mater. Sci. Eng. B 2003, 103, 140.

[22] H. Zois, L. Apekis, Y. P. Mamunya, J. Appl. Polym. Sci. 2003, 88, 3013.

[23] Z. Ounaies, C. Park, J. Harrison, Peter. Lillehei, J. Thermoplast. Compos. Mater. 2008, 21, 393.

[24] A. Chaipanich, N. Jaitanong, R. Yimnirun, Ceram. Int. 2011, 37, 1181.

[25] W. K. Sakamoto, P. Marin-Franch, D. K. Das-Gupta, Sens. Actuat. A 2002, 100, 165.

[26] G. Rujijanagul, S. Jompruan, A. Chaipanich, Curr. Appl. Phys. 2008, 8, 359.

[27] X. F. Liu, C. X. Xiong, H. J. Sun, L. J. Dong, R. Li, Y. Liu, Mater. Sci. Eng. B 2006, 127, 261.

[28] S. Banerjee, K. A. Cook-Chennault, Compos. Part A 2012, $43,1612$.

[29] L. Seveyrat, A. Chalkha, D. Guyomar, L. Lebrun, J. Appl. Phys. 2012, 111, 104904.

[30] K. Wongtimnoi, B. Guiffard, A. Bogner-Van de Moortèle, L. Seveyrat, C. Gauthier, J.-Y. Cavaillé, Compos. Sci. Technol. 2011, 71, 885.

[31] B. Guiffard, L. Seveyrat, G. Sebald, D. Guyomar, J. Phys. D Appl. Phys. 2006, 39, 3053.

[32] M. Hori, T. Aoki, Y. Ohira, S. Yano, Compos. Part A 2001, 32, 287.

[33] S. Tian, F. Cui, X. Wang, Mater. Lett. 2008, 62, 3859.

[34] S. Tian, X. Wang, J. Mater. Sci. 2008, 43, 4979. 
[35] S. Kirkpatrick, Rev. Mod. Phys. 1973, 45, 574.

[36] G. Stauffer, Introduction to the Percolation Theory, Taylor \& Francis, London 1985, 87.

[37] D. Carponcin, E. Dantras, G. Aridon, F. Levallois, L. Cadiergues, C. Lacabanne, Compos. Sci. Technol. 2012 72, 515 .

[38] V. Levchenko, Ye. Mamunya, G. Boiteux, M. Lebovka, P. Alcouffe, G. Seytre, E. Lebedev, Eur. Polym. J. 2011, 47, 1351.
[39] L. Liu, J. C. Grunlan, Adv. Funct. Mater. 2007, 17,2343.

[40] O. Meincke, D. Kaempfer, H. Weickmann, C. Friedrich, M. Vathauer, H. Warth, Polymer 2004, 45, 739.

[41] W. K. Sakamoto, P. Marin-Franch, D. K. Das-Gupta, Sens. Actuat. A Phys. 2002, 100, 165.

[42] M. R. Soares, A. M. R. Senos, P. Q. Mantas, J. Eur. Ceram. Soc. 2000, 20, 321.

[43] E. Flahaut, R. Bacsa, A. Peigney, C. Laurent, Chem. Commun. 2003, 21, 1443. 